a translation -such as "perturbation" for "scattering", "acoustic potential" for "velocity potential", cause a little awkwardness until they are assimilated.

The book is well produced and clearly printed, and many acousticians, particularly those studying wave propagation in materials, would find it a valuable work of reference. Derwent M. A. Mrercer

\section{TIDES AND WAVES}

\section{Coastal Hydraulics}

By A. M. Muir Wood. (Macmillan Civil Engineering Hydraulies.) Pp. xii +187. (Macmillan: London, October 1969.) $55 s$.

In the past twenty-five years, scientists have tried to understand and explain quantitatively a wide variety of oceanographic phenomena. The lure of the open sea is so strong, however, that most of the money has gone towards deep water research and there has been too little attention to coasts and beaches. This impression is strengthened after reading this little book, written by a practising civil engineer. However important it is to know the physics of the deep oceans for future developments, for the present, the economically much more important zone near the shore has been systematically ignored.

The book, intended for students and for practising engineers, is in effect a useful guide to the existing literature, particularly that published in Britain. It therefore serves as a foil to Wiegel's Oceanographical Engineering which is rather too strongly dependent on American practice. There is regrettably too little reference to Dutch work. The author clearly loves his algebra, and the reader is treated to a number of classical derivations of tidal motion theory and wave theory; the student, reading this part of the work for the first time, will have difficulty in understanding the nomenclature, for definitions of many important ideas are sadly lacking. There are, however, a number of worked examples of the applications of the theories to situations which might arise in practice, though largely because of the lack of measurements, many of them (and other examples in the text) do not have confirmatory experimental evidence that the predictions are correct.

For the work of one who has been concerned with civil enginearing works on coasts, there is a regrettable shortage of drawings, diagrams and data from real situations. The value of this book would have been considerably enhanced if much more information had been presented on the performance of structures under these conditions. For example, on page 139, dealing with wave impact pressures, the remark is made that "ill-designed or badly constructed lift joints (in concrete sea walls) become rapidly exploited by the sea"; how much better it would have been if drawings or photographs of both good and bad joints, exploited or not, were given; the book would have paid for itself if this information had been given. The book, by its restriction on length, also often breaks down just when it becomes useful; for example, on page 26, a specific limitation is made that "complexities of tidal movements in estuaries are beyond the range of the book"; surely estuaries are precisely where a great majority of coastal engineering structures are placed and where tidal movements are crucially important. It is comments such as these that give an impression that the book is a set of exercises rather than a compilation of value to real situations.

For the small number of civil engineering undergraduates who wish to study this kind of work, the book may be an introduction, but for rigour of the proofs concerned, they would be better advised to consult Proudman's Dynamical Oceanography; and for completeness of information on engineering applications, Wiegel's Oceanographical Engineering.

\section{COST OF CHEAP POWER}

\section{Abundant Nuclear Energy}

(Proceedings of a Symposium held at Gatlinburg, Tennes. see, August 26-29, 1968.) Pp. vi +352 . (US Atomic Energy Commission, Division of Technical Information: Oak Ridge, May 1969.) \$3.

Everybody recognizes the immense changes which have come about as a consequence of the discorery of how to use the large sources of energy available to us and how essential these are to civilization as we know it at present. It is reasonable to suppose that power will become even more abundant and cheaper in the future and this book describes a symposium whose organizers felt that it would be worth while to examine the implications of the avail ability of cheap electricity - and waste heat -.. from future nuclcar power complexes.

The book seems to fall between two stools. It starts off with two revicw papers, one on the availability and cost of power, the other dealing generally with the consequences of cheap power on energy-intensive processes. These are then examined individually. The intention no doubt was to point out dramatic changes, if any, which could be expected; but, for the most part, they describe the present techniques of winning and purifying the various materials in question. Certainly the costs of the various stages are brought out but my impression is that the book will not be of great use to the chemical engineer, the metallurgist or the nuclear engineer, but it may have value as a textbook. Other papers describe processes which could use the waste heat from reactors.

Most of the delegates attending the symposium- and all the speakers-were from the United States and the costs and forecasts in the book reflect US experience and views. J. A. Lane of the Oak Ridge National Laboratory traces in an interesting way the history of the sources and cost of power and then goes on to predict costs and consumption of electrical power into the early years of the next century. Of incidental interest is his estimate that an early power source in Egypt and elsewhere-slave labour - cost the equivalent of $\$ 1$ to $\$ 5$ per kilowatt hour. Nowadays, the per capita power consumption in the United States is the equivalent of 200 slaves at an annual cost of less than $\$ 100$. In his survey of electricity he points out that the consumption and real cost have respectively risen and fallen by more than one hundred times since 1880. His final prediction is that electricity will be available in $\mathrm{AD} 2000$ at costs ranging from $0 \cdot 15$ to 0.55 cents per kilowatt hour for industri and householders respectively; and much besides although a good deal of it has been given before.

Holmes reviews the effects of decreased electricity charges in various chemical and metallurgical processes. Following papers (not particularly technical) deseribe the processes and power consumption in the production of phosphorus, chlorine, acetylene, nitrogen fixation, hydrogen and oxygen by electrolysis and otherwise, arnmonia, aluminium, magnesium, iron and steel. Other papers discuss the possible use of waste heat combined with low cost electricity in space heating, marine chemical recovery, desalination and other fields. Discussion was generally in terms of the NUPLEX or agricultural industrial complex based on a nuclear power plant placed at places where there are abundant raw materials together with a need for fresh water and fertilizers. North African and Asian sites were referred to, although other speakers thought that such a complex should be set up in the United States first.

The meeting finished with a panel discussion of the implications for university nuclear engineering schools. The wide ranging discussion was not often on the subject and little of a positive nature emerged.

H. IV. WILSON 